\title{
Trip Generation Rates for Large Elevators: A North Dakota Case Study
}

\author{
Denver Tolliver \\ Alan Dybing \\ Subhro Mitra
}

Upper Great Plains Transportation Institute

North Dakota State University

Fargo, ND

December 2006 


\section{Disclaimer}

The contents of this report reflect the views of the authors, who are responsible for the facts and the accuracy of the information presented. This document is disseminated under the sponsorship of the Department of Transportation, University Transportation Centers Program, in the interest of information exchange. The United States government assumes no liability for the contents or use thereof. 


\section{EXECUTIVE SUMMARY}

Large grain elevators are major sources of truck traffic in many areas. Shuttle trains, a recent railroad innovation, have further concentrated truck deliveries at large elevators. These facilities-which have not been analyzed in previous trip generation studies - pose issues such as large truck access and pavement design.

In this paper, elevator trip generation equations are estimated from detailed facility, land-use, and highway traffic data in North Dakota. A trip attraction equation is used to explain the effects of elevator storage capacity and side track capacity on elevator throughput. Elevators are classified on the basis of track capacity as shuttle train, unit train, and multi-car. Shuttle-train elevators typically consign 110-car trains, while unit-train elevators consign 50- to 100-car trains. The analysis shows that large shuttle-train elevators may generate 35,000 to 40,000 loaded and empty truck trips per year. A large unit-train elevator may generate 20,000 annual trips.

The trucks are usually a mixture of combination 5-axle and single-unit trucks. On average, each truck generates 1.04 equivalent single-axle loads on flexible pavements. Thus, a large facility may generate much of the traffic load experienced by pavements in the area. Moreover, truck deliveries to elevators exhibit seasonal variation. Approximately $15 \%$ of the annual volume is delivered during a peak month. Thus, a large shuttle facility may generate 225 trucks per day during a peak harvest month. 


\section{TABLE OF CONTENTS}

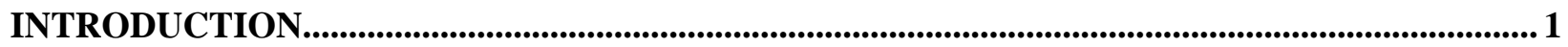

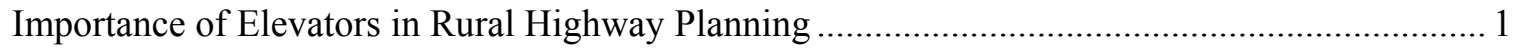

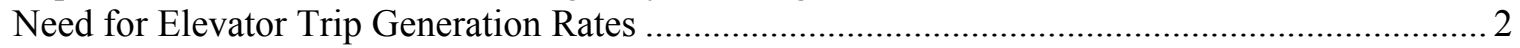

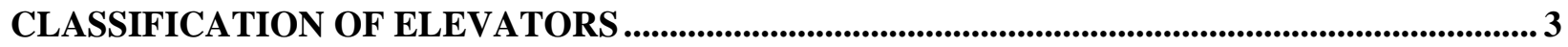

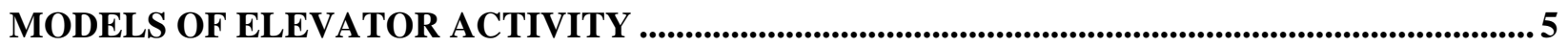

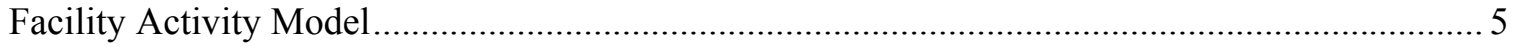

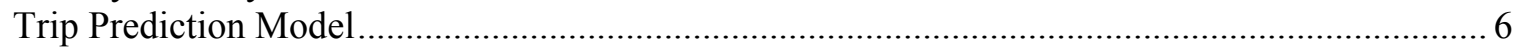

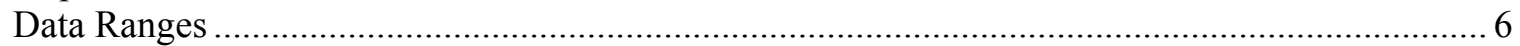

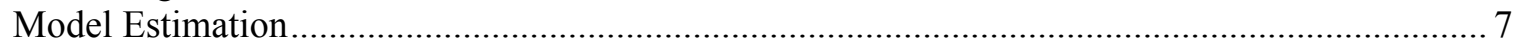

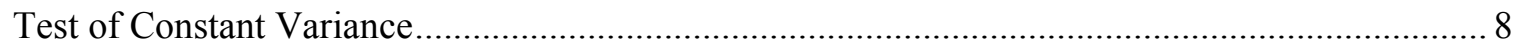

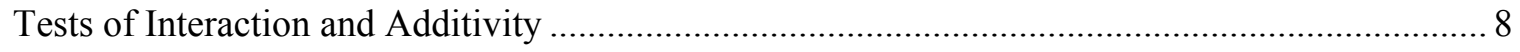

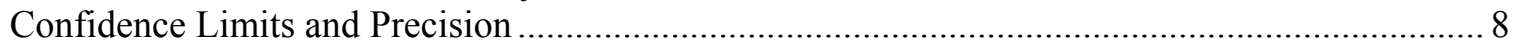

APPLYING THE TRIP GENERATION EQUATION ............................................................................. 11

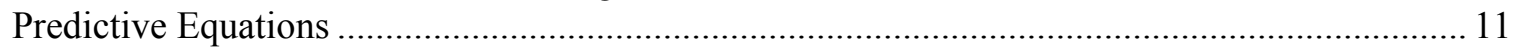

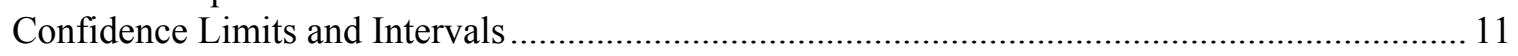

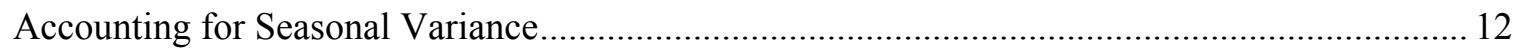

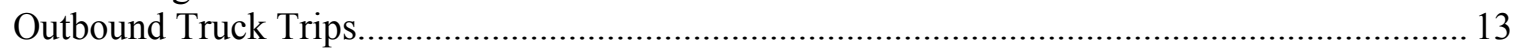

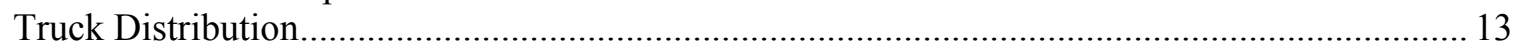

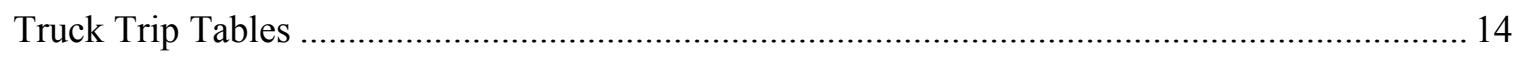

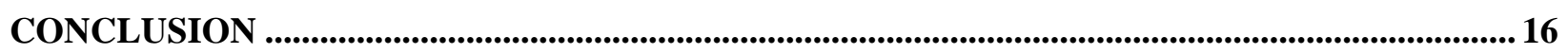

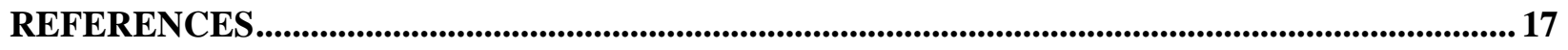




\section{LIST OF TABLES}

Table 1. Shuttle Elevator Volume and Peak Truck Traffic Based on Train Cycle.............................. 5

Table 2. Ranges of Throughput and Storage Capacities for Elevator Sample .................................... 7

Table 3. Parameter Estimates and Statistical Tests for Elevator Throughput Model ........................... 7

Table 4. $\quad$ Predicted Throughput and Confidence Interval Limits for Shuttle Elevators ........................11

Table 5. Predicted Throughput and Confidence Interval Limits for Unit-Train Elevators ................... 12

Table 6. Percent of Crops Marketed by Month in Crop Year 2003-2004 .......................................... 12

Table 7. Percentages of Single-Unit and Combination Trucks in the Vicinities of Elevators .............. 13

Table 8. Predicted Equivalent Truck Trips and ESAL Factors for Shuttle Elevators .......................... 14

Table 9. Predicted Equivalent Truck Trips and ESAL Factors for Unit-Train Elevators .................... 14

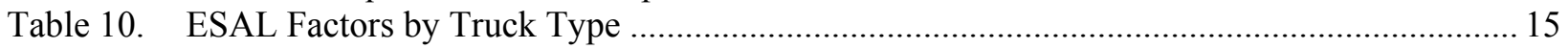

\section{LIST OF FIGURES}

Figure 1. Variable Cost Relationships for Rail Shipment Sizes ........................................................ 1

Figure 2. Mean Elevator Storage Capacity and Throughput ..................................................... 4

Figure 3. Predicted Values and 95\% Confidence Limits for Shuttle Elevators ..................................... 9

Figure 4. Plot of Residuals Against Predicted Values for Elevator Activity Model............................. 10 


\section{INTRODUCTION}

Trip generation rates are widely used for site impact analysis, travel demand forecasting, and highway sketch planning. Trip rates for warehouses are published by the Institute of Transportation Engineers (1) and the Transportation Research Board (2). In these studies, daily vehicle trips are based on number of employees, square feet of floor space, or land area. Although grain elevators are classified as warehouses, these facilities are much different from manufacturing warehouses and distribution centers. Typically, employees and floor space are not good indicators of the daily trips generated by grain elevators. This paper supplements existing studies by providing specific trip generation equations for these facilities.

\section{Importance of Elevators in Rural Highway Planning}

Large elevators are often the primary source of truck traffic in rural grain-producing regions. These facilities pose two key highway planning issues: large truck access and pavement design. Many trucks serving these facilities are long combination trucks that are less maneuverable and responsive than singleunit trucks. Deliveries of grain vary considerably during the year, creating higher weekday traffic levels during peak months. Most grain trucks operate at or near the maximum gross vehicle and axle weight limits. A large proportion of the annual equivalent single-axle loads (ESALs) in rural areas are attributable to these trucks.

Although large elevators pose highway planning issues, they are key elements of agricultural supply chains. During the last 10 years, many "shuttle-train" elevators have been constructed in the Great Plains. These elevators cyclically load trains of 100 cars or more, which are moved expeditiously by rail to major export locations or domestic markets. As shown in Figure 1, shuttle trains are much more efficient than traditional single- or multi-car railroad services.

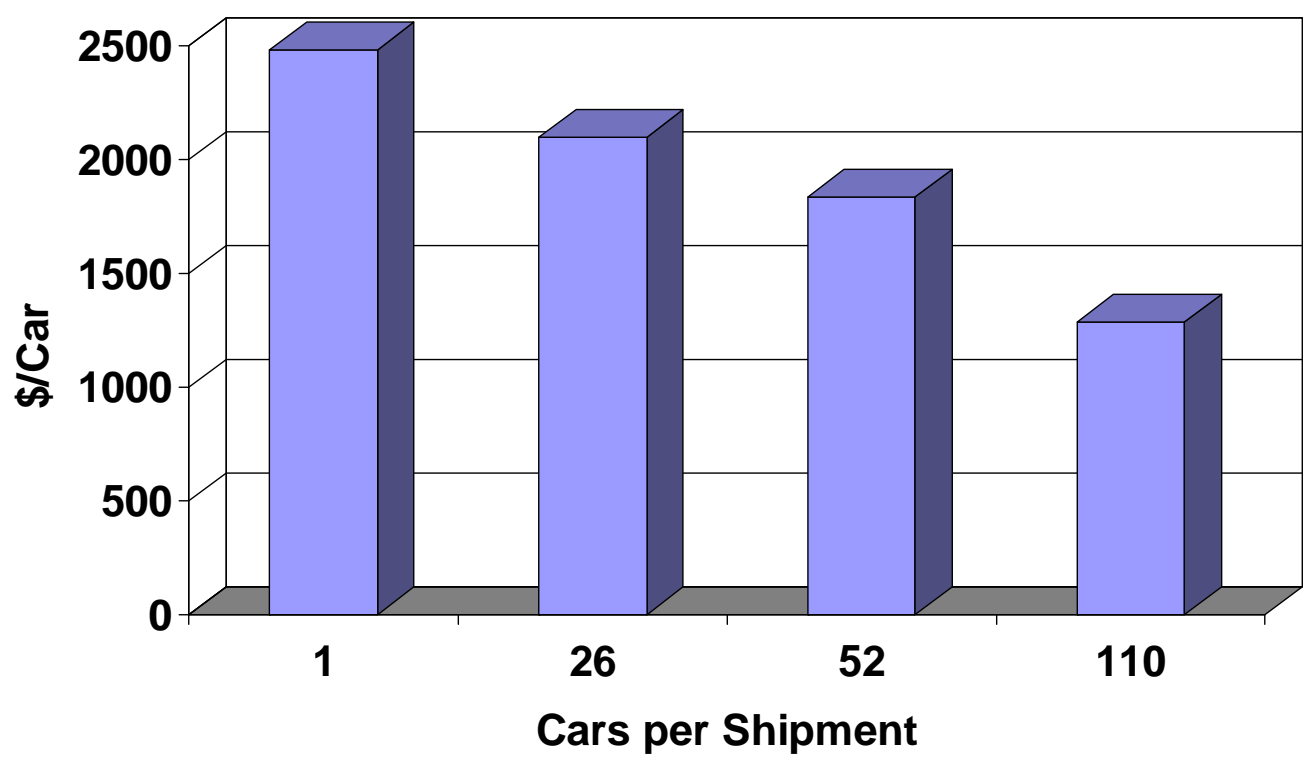

Figure 1. Variable cost relationships for rail shipment sizes.

Computed from URCS: Distance $=1,370$ miles, including 60 way train miles. 
These efficiency gains are important to the agricultural economies of many states. However, shuttle elevators have several implications for highway planning. First, the high throughput of these facilities necessitates many truck deliveries to a single location. A large elevator may handle 15 million bushels a year. This volume is roughly equivalent to 33,000 loaded and empty 3-S2 trucks (trucks with a 3-axle tractor and 2-axle semitrailer). Second, shuttle facilities are located to optimize railroad and crop access. Few of them are located on interstate or principal arterial highways. Third, most of the outbound traffic moves by rail. In effect, shuttle trains substitute for long-distance truck movements from elevators to markets. In this respect, shuttles are beneficial to transportation agencies and highway users.

\section{Need for Elevator Trip Generation Rates}

Highway traffic studies, elevator surveys, and elevator market studies estimate trips to new or expanded elevators. Highway traffic counts are useful. However, a new facility may not reach its traffic potential for some time. Moreover, farm-to-elevator movements exhibit seasonal fluctuations that limit the usefulness of short-term traffic counts. Although elevator surveys are advantageous, they can be time consuming and difficult. Throughput volumes and traffic data are often viewed as confidential. Elevator market studies provide the most detailed forecasts of potential throughput; however, these studies require the demarcation of a market region based on the locations, sizes, and bid prices of competing elevators (3). Market territory studies are meticulous and specific to the facility and its competitive landscape.

Clearly, a quick forecasting method is needed. This paper presents a generalized approach for highway sketch planning, facility impact analysis, and traffic modeling. The objectives of the study are to 1) estimate trip-rate equations for elevator facilities, 2) provide estimating procedures that are generally transferable, and 3) provide estimating techniques that can be readily and quickly applied using publiclyavailable data. 


\section{CLASSIFICATION OF ELEVATOR ACTIVITY}

In this study, elevators are classified according to railroad track capacity-i.e., the maximum number of cars that can be spotted by the railroad without separating the car block-and storage capacity. These criteria are good indicators of an elevator's potential activity and throughput.

New or expanded facilities may be classified according to their highest possible railroad service level: multi-car, unit train, or shuttle. In this study, multi-car elevators are defined as those that can accommodate fewer than 50 cars in a single switch. While these elevators may ship significant volumes, they are unlikely to participate in large export or domestic movements. Unit-train elevators can accept 50 to 100 cars at a time. These shippers may consign trainloads as well as mini trains (e.g., 50- to 54-car shipments). However, the trainloads are not shuttle trains-i.e., they do not cycle between origin and destination.

Shuttle-train elevators have sufficient track space for more than 100 cars. These high-throughput elevators are designed to load 110-car trains in fewer than 15 hours. Some shuttle-train elevators are built with loop tracks that allow for continuous loading of trains without uncoupling the cars. A facility without loop tracks needs roughly 1.5 miles of double-ended side track and a parallel 55-car track to temporarily hold loaded cars.

In addition to side track capacity, elevators may be classified according to bushels of storage capacity. Minimum elevator storage requirements are based on train size, number of commodities handled, and services performed (such as blending of grains). A 110-car train represents about 440,000 bushels of corn. In comparison, a 55-car shipment represents about 220,000 bushels. However, only the minimum storage requirements are determined by train size. Elevator capacity is partly a function of the expected throughout of the facility. Shuttle elevator capacities typically range from one million to over three million bushels. An elevator that ships more than one unit-train per week-or combinations of multi-car and unit-train shipments - may need a half-million bushels of storage. Elevators with greater capacities can store grain for several weeks, which is especially important during the intense 2-month harvest period when more than $25 \%$ of the crop is typically moved from farms to elevators. Figure 2 shows a comparison of the mean elevator storage capacity and grain throughput. 


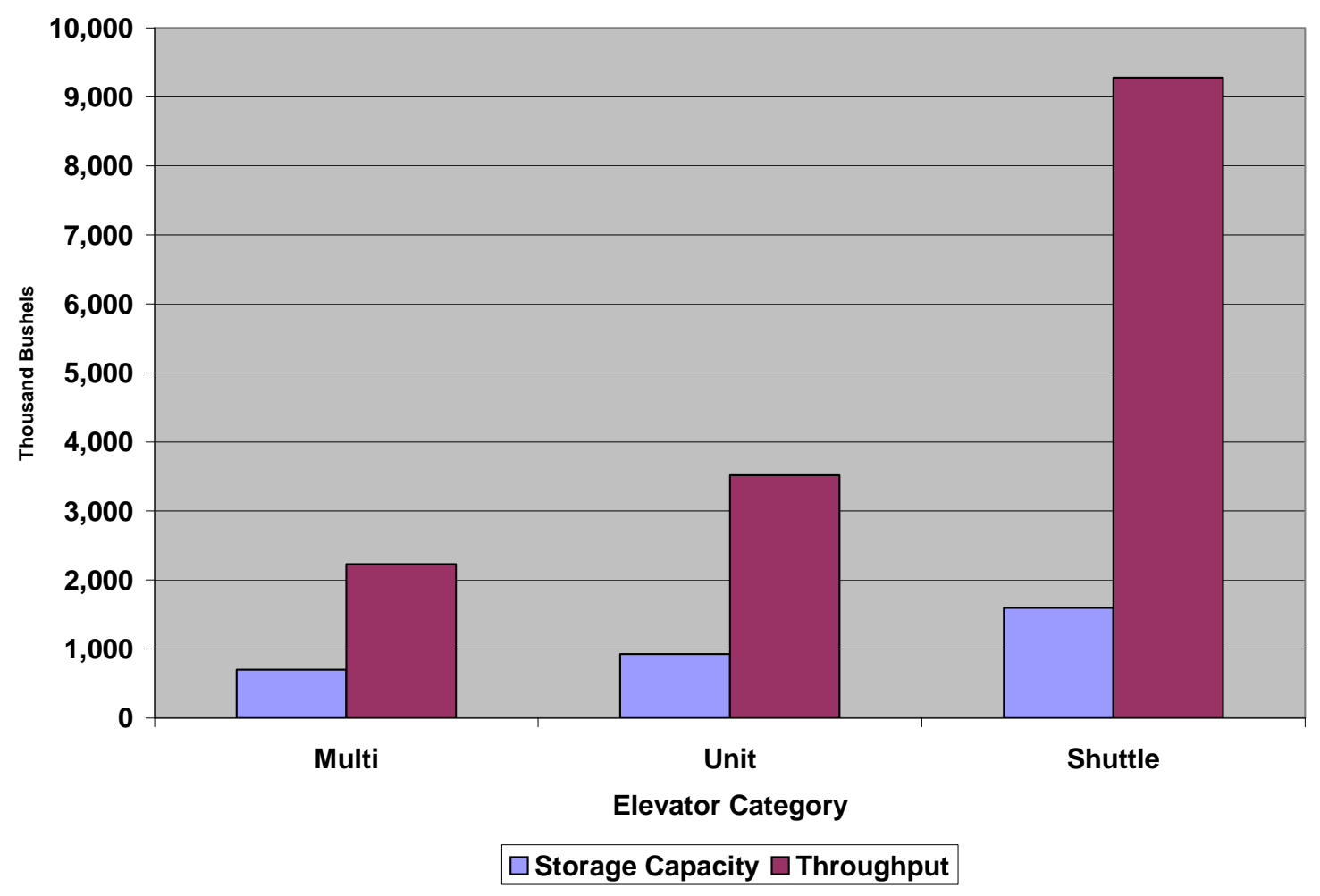

Figure 2. Mean Elevator Storage Capacity and Throughput 


\section{MODELS OF ELEVATOR ACTIVITY}

\section{Facility Activity Model}

The activity of a pure shuttle-train elevator can be modeled as a function of railroad service. Throughput is very dependent upon train cycle time. Table 1 shows an example of an elevator that ships 110-car corn trains exclusively. Each train holds approximately 436,000 bushels. With a train cycle of 14 days, the facility can originate 11.4 million bushels of corn per year. However, with a train cycle of 10 days, the same facility can originate 15.7 million bushels per year.

Table 1. Shuttle Elevator Volume and Peak Truck Traffic Based on Train Cycle

\begin{tabular}{|l|c|r|r|}
\hline 1. Train Cycle (days) & Varies with distance and congestion & 14 & 10 \\
\hline 2. Trains per Year & $365 /$ L. 1 & 26 & 36 \\
\hline 3. Bushels per Train & 110 cars @ 3,964 bushels & 436,070 & 436,070 \\
\hline 4. Bushel Throughput (000) & L. 2 x L. 3 & 11,338 & 15,699 \\
\hline 5. Bushels per 3-S2 Truck & At 80,000 lb gross weight & 890 & 890 \\
\hline 6. Loaded 3-S2 Trucks & L. 4 x 1000 / L. 5 & 12,739 & 17,639 \\
\hline 7. Loaded \& Empty Trucks & L.6* 2 & 25,478 & 35,278 \\
\hline 8. Peak Month Traffic Percent & Ref. (3) & $15 \%$ & $15 \%$ \\
\hline 9. Delivery Days per Month & & 26 & 26 \\
\hline 10. Peak Trucks per Day & L.7 x L.8 / L.9 & 147 & 204 \\
\hline
\end{tabular}

The hypothetical volumes shown in Table 1 can be converted to 3-S2 trucks by assuming a typical load of 890 bushels. This load factor is realized when the gross weight of the truck is limited to 80,000 pounds. Fifteen percent of the annual grain crop in a production area may be delivered to elevators during the peak harvest month (4). If the deliveries are spread over 26 days of the peak month, approximately $1503-\mathrm{S} 2$ trucks per day could move into and out of an elevator that ships 26 shuttle trains per year. Approximately 2003 -S2 trucks per day could move into and out of an elevator that ships 36 shuttle trains per year. If the trucks are a mixture of single-unit and 3-S2 trucks, then the number of daily trucks could be greater.

Elevators that overlap shuttle cycles or ship trains to several markets may generate higher traffic levels. For example, an elevator that ships 46 shuttle trains per year could generate 2603 -S2 trucks per day during the peak month. Although peak daily traffic is an important factor, the equivalent single-axle loads (ESALs) generated by the trucks are also of interest. Each 3-S2 truck generates approximately 2.4 ESALs on flexible pavements. Truck deliveries to an elevator that ships 36 shuttle trains per year could result in 85,000 annual ESALs. Because traffic may enter the facility from several directions, the ESALs could be distributed over several access highways. 


\section{Trip Prediction Model}

The shuttle-train requirements model is a useful barometer of large elevator activity. However, it doesn't consider variations in elevator size or levels of participation in the shuttle program. Moreover, it is sensitive to railroad network congestion and level of service.

In this section of the paper, an elevator activity model is estimated using regression analysis. The model predicts elevator throughput as a function of track capacity (multi car, unit train, or shuttle) and elevator storage capacity. The regression model is estimated with data from 121 elevators in North Dakota that handled at least 1 million bushels of grain in 2004, a year in which overall crop production was typical of the 10-year period from 1995 through 2004. These elevators are public warehouses that report shipments to the North Dakota Public Service Commission. This information is confidential and cannot be listed. However, the throughput data are used in conjunction with publicly-available information on track and storage capacity to develop a predictive model (Equation 1).

$$
\text { (1) } \ln (\text { bu })_{i}=\beta_{0}+\beta_{1} \text { Multi }_{i}+\beta_{2} \text { Unit }_{i}+\beta_{3} \ln (\text { cap })_{i}+\varepsilon_{i}
$$

Where:

$\operatorname{Ln}(b u)=$ natural logarithm of bushels

Multi $=$ an indicator variable equal to 1 if the facility is a multi-car elevator ( 0 otherwise)

Unit $=$ an indicator variable equal to 1 if the facility is a unit-train elevator ( 0 otherwise)

$\operatorname{Ln}($ cap $)=$ natural logarithm of elevator capacity

$\varepsilon=$ an error term that is assumed to be normally distributed and constant over the range of

capacity values

The subscript $i$ denotes elevator $i$

Equation 1 is a double-log model. This functional form is used for two reasons. First, the variance of throughput increases with storage capacity, which could violate the constant-variance assumption of leastsquares regression. Second, the double-log form allows the interpretation of $\beta_{3}$ as the elasticity of throughput with respect to capacity.

\section{Data Ranges}

Table 2 shows the ranges of throughput and storage capacity within and among the subgroups of elevators. Shuttle-train elevator capacities range from 0.5 million bushels to 3.7 million bushels, while throughput ranges from 3.7 million bushels to 16.3 million bushels. Unit-train elevator capacities range from 0.3 million bushels to 3.4 million bushels, while throughput ranges from 1.1 million bushels to 10.2 million bushels. Multi-car elevator capacities range from 0.2 million bushels to 2.0 million bushels, while throughput ranges from 1.0 million bushels to 7.2 million bushels. 
Table 2. Ranges of Throughput and Storage Capacities for Elevator Sample

\begin{tabular}{|c|c|c|c|c|}
\hline & Mean & Std Dev & Minimum & Maximum \\
\hline \multicolumn{5}{|l|}{ Multi Car (n=50) } \\
\hline Storage Capacity (Thou. Bu.) & 701 & 417 & 176 & 2035 \\
\hline Throughput (Thou. Bu.) & 2,228 & 1,531 & 1,045 & 7,199 \\
\hline \multicolumn{5}{|l|}{ Unit Train $(n=51)$} \\
\hline Storage Capacity (Thou. Bu.) & 929 & 598 & 257 & 3,357 \\
\hline Throughput (Thou. Bu.) & 3,520 & 2,114 & 1,100 & 10,235 \\
\hline \multicolumn{5}{|l|}{ Shuttle $(n=20)$} \\
\hline Storage Capacity (Thou. Bu.) & 1,596 & 951 & 506 & 3,737 \\
\hline Throughput (Thou. Bu.) & 9,280 & 3,570 & 3,671 & 16,286 \\
\hline
\end{tabular}

\section{Model Estimation}

In the model, $\beta_{3}$ represents the slope of the regression line or the rate at which the log of throughput increases with the $\log$ of storage capacity. $\beta_{0}$ is the intercept of the regression line for shuttle-train elevators. $\beta_{1}$ and $\beta_{2}$ represent shifts in the intercept attributable to lower levels of track capacity for multicar and unit-train shippers. The statistical significance of the parameter estimates are gauged through hypothesis tests. In the case of $\beta_{3}$, the null hypothesis is that the slope of the regression line is not significantly different from zero. The null hypotheses for $\beta_{1}$ and $\beta_{2}$ are that the intercept terms for multi-car and unit-train elevators are not significantly different from the intercept for shuttle-train elevators.

The t-statistic of each explanatory variable is computed by dividing its parameter estimate by its standard error (Table 3). The corresponding p-value represents the probability of observing a greater absolute value of $t$ if the null hypothesis is true-i.e., the parameter estimate is not significantly different from zero. As shown in Table 2, the parameter estimates are all highly significant at an $\alpha$ of 0.01 , and the p-values of less than 0.0001 strongly suggest that the statistical relationships do not occur by chance.

The model fits the data well. The F-value (which measures the overall goodness of fit) is 71.64. The probability of observing a greater F-value when the null hypothesis is true (e.g., there is no relationship between the log of bushels and the log of elevator capacity and track capacity) is less than 0.001 . The Rsquare of the model is 0.65 . The adjusted R-square is 0.64 . The model explains a little less than two-thirds of the variation in elevator throughput.

Table 3. Parameter Estimates and Statistical Tests for Elevator Throughput Model

\begin{tabular}{|l|r|r|r|r|}
\hline Variable & Parameter Estimate & Standard Error & t-value & Pr $>|\mathbf{t}|$ \\
\hline Intercept & 8.86876 & 1.01782 & 8.71 & $<.0001$ \\
\hline Ln $($ cap $)$ & 0.50309 & 0.07175 & 7.01 & $<.0001$ \\
\hline Multi & -1.10339 & 0.13108 & -8.42 & $<.0001$ \\
\hline Unit & -0.78958 & 0.12336 & -6.40 & $<.0001$ \\
\hline
\end{tabular}




\section{Test of Constant Variance}

An assumption of the model is that the variance of the error term is constant over the range of storage capacities of the elevators. The White and Bruesch-Pagan tests are used to gauge this assumption. Both tests are described in reference (5). The p-values of the Chi-Square statistics are 0.90 and 0.43 for the White and Bruesch-Pagan tests, respectively. The high p-values indicate that there is little evidence to reject the assumption of constant variance. This conclusion is bolstered by a plot of the residuals of the regression against the predicted values, as shown in Figure 1.

\section{Tests of Interaction and Additivity}

An assumption of the regression model is that the slope or rate of change of throughput with respect to storage capacity is the same for each track class. This belief is tested by adding two interaction terms to the model. Z1 is defined as $\ln (\text { cap })^{*}$ Multi. Z2 is computed as $\ln (c a p)^{*}$ Unit. Using Equation 2, a partial F-test is performed to determine if interaction exists.

$$
\text { (2) } F=\frac{\left(S S E_{R}-S S E_{F}\right) /(K-L)}{M S E_{F}}=\frac{(23.0494-22.34768) /(5-3)}{.19433}=1.0855
$$

Where:

$\mathrm{SSE}_{\mathrm{R}}=$ Error sum of squares for the reduced model without $Z_{1}$ and $Z_{2}$

$\mathrm{SSE}_{\mathrm{F}}=$ Error sum of squares for the full model including $Z_{1}$ and $Z_{2}$

$\mathrm{K}=$ Independent variables in the full model

$\mathrm{L}=$ Independent variables in the reduced model

$\mathrm{MSE}_{\mathrm{F}}=$ Mean square error for the full model

The p-value of 0.169 for F suggests that the null hypothesis of "no interaction" cannot be rejected. The effects of storage and track capacity on elevator throughput are additive. Moreover, the assumption of a common slope coefficient is valid for all track capacity classes. The parameter estimate of 0.50309 for $\ln (c a p)$ indicates that elevator throughput increases by $0.5 \%$ for each $1 \%$ increase in storage capacity.

\section{Confidence Limits and Precision}

The $\mathrm{R}^{2}$ of the regression does not tell if the model is a good predictive tool. One indicator of model precision is the coefficient of variation, which is computed as the root mean square error of the regression (0.4438510) divided by the mean log of throughput (14.89937) multiplied by 100. In essence, the coefficient of variation describes the error about the regression line as a percentage of the dependent variable mean. The coefficient of variation for the elevator throughput model is $2.98 \%$, which suggests that the regression model may be a good predictor.

Figure 3 shows the predicted values and confidence interval limits (CIL) for the mean responses of shuttle. The lower $95 \%$ confidence limit $(\mathrm{L} 95 \% \mathrm{M})$ and the upper 95\% confidence limit $(\mathrm{U} 95 \% \mathrm{M})$ provide a confidence interval about the regression line. As shown in Figure 3, the confidence interval limits are relatively uniform throughout the range of capacities. 


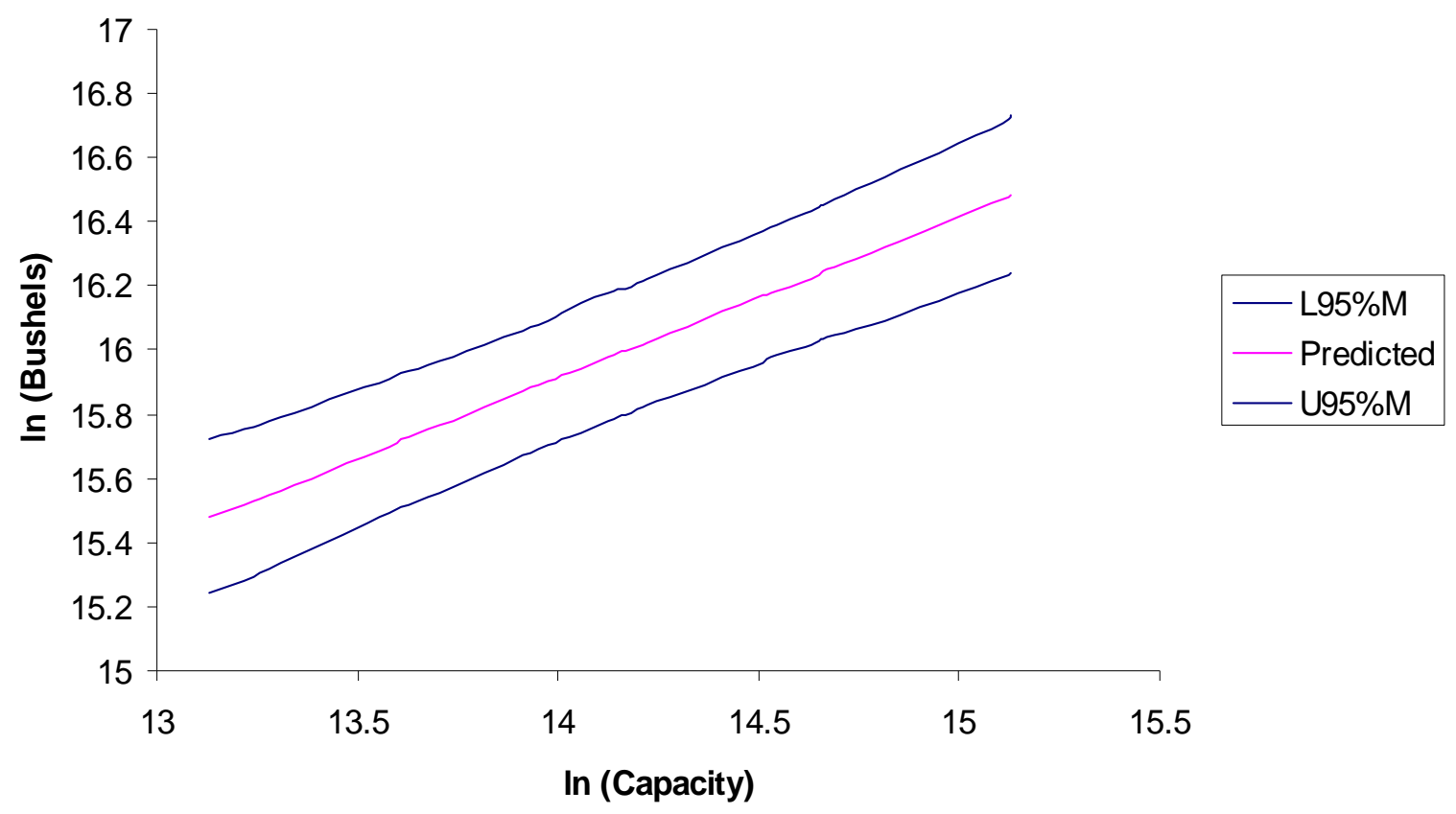

Figure 3. Predicted Values and 95\% Confidence Limits for Shuttle Elevators

The PRESS statistic is another indicator of whether the model is likely to be a good predictor. A PRESS residual is computed for each observation when the observation is not used to estimate the parameters. The PRESS statistic is the sum of the PRESS residuals. In this case, the PRESS statistic of 24.655 is very close

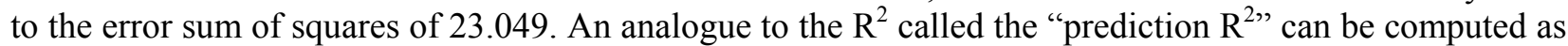
1 - (PRESS /Total Sum of Squares). For the elevator throughput model, the prediction $\mathrm{R}^{2}$ is .62, which is only slightly less than the $\mathrm{R}^{2}$ of 0.64 . 


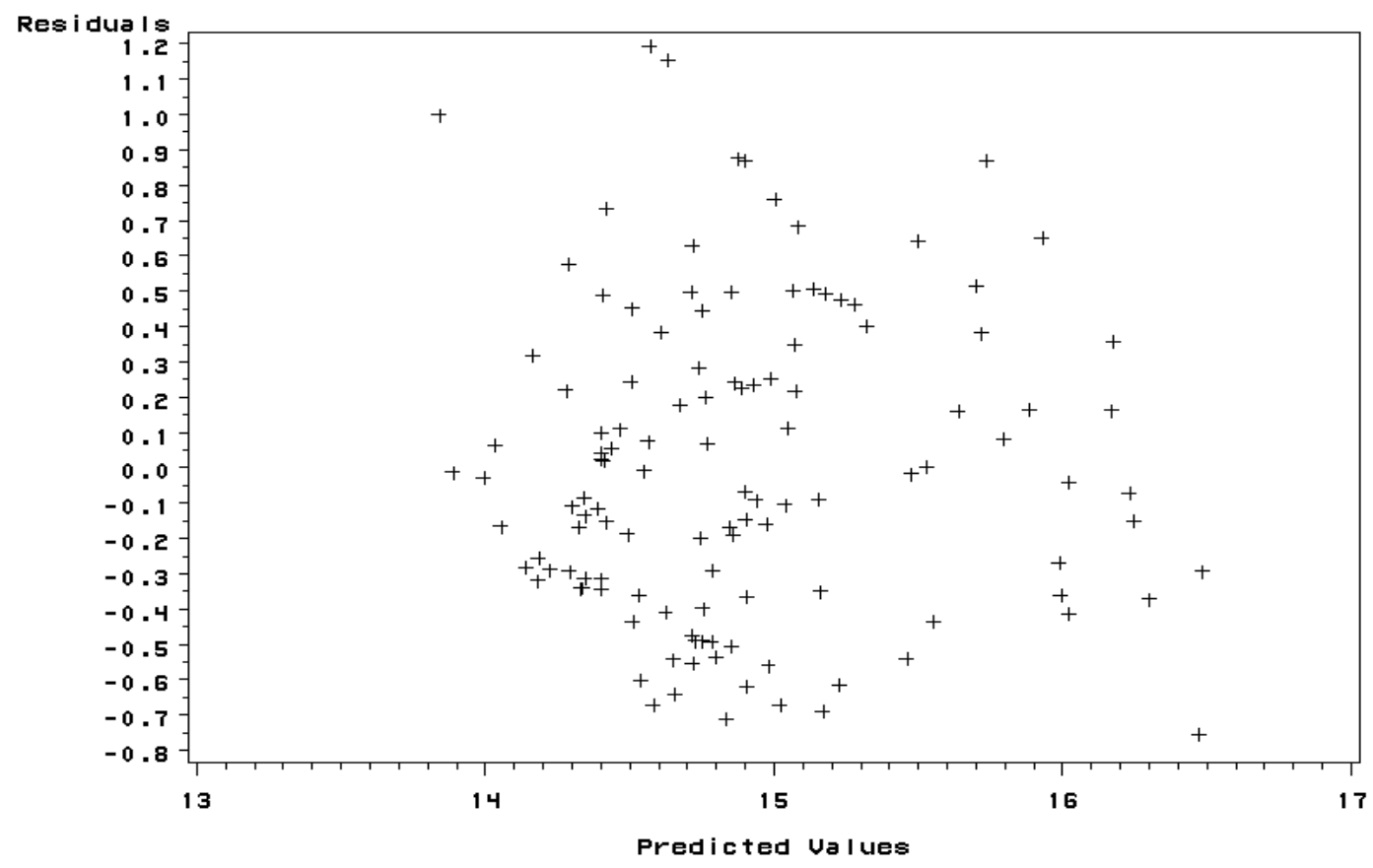

Figure 4. Plot of Residuals Against Predicted Values for Elevator Activity Model 


\section{APPLYING THE TRIP GENERATION EQUATIONS}

\section{Predictive Equations}

The predictive equations for annual truck deliveries to an elevator based on track capacity class and storage capacity are as follows:

(3) Shuttle $=\exp (8.86876+0.50309 * \ln ($ cap $)) / \mathrm{BT} * \mathrm{ER}$

(4) Unit $=\exp (8.07918+0.50309 * \ln ($ cap $)) / \mathrm{BT} * \mathrm{ER}$

(5) $\quad$ Multi $=\exp (7.76537+0.50309 * \ln ($ cap $)) / \mathrm{BT} * \mathrm{ER}$

Where:

$$
\begin{aligned}
& \mathrm{BT}=\text { Bushels per truck } \\
& \mathrm{ER}=\text { Empty return multiplier }
\end{aligned}
$$

BT is assumed to be 890 for a 3-S2 truck. However, BT may be a weighted average or value for an alternative truck type. An empty return multiplier of 2 indicates that the trucks are not reloaded at the elevator to transport commodities to farms. If this assumption is invalid, then a lower ER should be used.

\section{Confidence Limits and Intervals}

Table 4 shows the predicted value and upper and lower 95\% confidence interval limits for shuttle-train elevators with various storage capacities. The confidence limits correspond to the mean predicted response for all elevators of a given capacity. For example, the mean predicted throughput for shuttle elevators with 2 million bushels of storage capacity is 10.5 million bushels. The lower 95\% CIL for shuttle elevators with 2 million bushels of storage capacity is 8.6 million bushels. The upper 95\% CIL for shuttle elevators with 2 million bushels of storage capacity is 12.9 million bushels. Table 5 shows analogous values for unit-train elevators.

Table 4. Predicted Throughput and Confidence Interval Limits for Shuttle Elevators

\begin{tabular}{|c|c|c|c|}
\hline $\begin{array}{c}\text { Elevator Capacity } \\
\text { (Thou. Bushels) }\end{array}$ & $\begin{array}{c}\text { Lower 95\% CIL for } \\
\text { Mean }\end{array}$ & $\begin{array}{c}\text { Predicted Throughout } \\
\text { (Thou. Bushels) }\end{array}$ & $\begin{array}{c}\text { Upper 95\% CIL } \\
\text { for Mean }\end{array}$ \\
\hline 1,000 & 6,064 & 7,416 & 9,069 \\
\hline 1,250 & 6,814 & 8,298 & 10,103 \\
\hline 1,500 & 7,467 & 9,095 & 11,075 \\
\hline 1,750 & 8,047 & 9,828 & 12,002 \\
\hline 2,000 & 8,569 & 10,511 & 12,892 \\
\hline 2,250 & 9,045 & 11,153 & 13,750 \\
\hline 2,500 & 9,484 & 11,760 & 14,580 \\
\hline 2,750 & 9,892 & 12,337 & 15,386 \\
\hline 3,000 & 10,274 & 12,889 & 16,169 \\
\hline 3,250 & 10,633 & 13,419 & 16,933 \\
\hline 3,500 & 10,973 & 13,929 & 17,678 \\
\hline 3,700 & 11,233 & 14,324 & 18,263 \\
\hline
\end{tabular}


Table 5. Predicted Throughput and Confidence Interval Limits for Unit-Train Elevators

\begin{tabular}{|c|c|c|c|}
\hline $\begin{array}{c}\text { Elevator Capacity } \\
\text { (Thou. Bushels) }\end{array}$ & $\begin{array}{c}\text { Lower 95\% CIL for } \\
\text { Mean }\end{array}$ & $\begin{array}{c}\text { Predicted Throughout } \\
\text { (Thou. Bushels) }\end{array}$ & $\begin{array}{c}\text { Upper 95\% CIL } \\
\text { for Mean }\end{array}$ \\
\hline 500 & 2,067 & 2,376 & 2,730 \\
\hline 750 & 2,576 & 2,914 & 3,296 \\
\hline 1,000 & 2,964 & 3,367 & 3,826 \\
\hline 1,250 & 3,277 & 3,767 & 4,331 \\
\hline 1,500 & 3,542 & 4,129 & 4,813 \\
\hline 1,750 & 3,775 & 4,462 & 5,275 \\
\hline 2,000 & 3,983 & 4,772 & 5,717 \\
\hline 2,250 & 4,173 & 5,064 & 6,143 \\
\hline 2,500 & 4,349 & 5,339 & 6,554 \\
\hline 2,750 & 4,513 & 5,602 & 6,952 \\
\hline 3,000 & 4,667 & 5,852 & 7,338 \\
\hline 3,250 & 4,812 & 6,093 & 7,714 \\
\hline
\end{tabular}

As shown in Table 4, the predicted throughput of a shuttle-train elevator with 3.7 million bushels of storage capacity is 14.3 million bushels. Approximately the same estimate could be derived using the method shown in Table 2, assuming a train cycle of 12 days. Although the model appears to be a good predictive tool, extrapolation beyond the data range is not advised. Instead, the approach shown in Table 2 should be used to extrapolate on the basis of expected shuttle trains per year.

\section{Accounting for Seasonal Variance}

As noted earlier, truck deliveries to elevators are expected to vary considerably during the year. Given the mix of crop production and geographic location, the peak month may be August, September, or October. Table 6 shows the monthly distribution of deliveries for crops produced in North Dakota. Analogous information can be compiled for any state using information from the National Agriculture Statistics Service (NASS) of the United States Department of Agriculture. This information can be used to adjust the procedure illustrated in Table 2.

Table 6. Percent of Crops Marketed by Month in Crop Year 2003-2004 (5)

\begin{tabular}{|l|c|c|c|c|c|c|c|c|c|c|c|c|}
\hline Crop & Jan & Feb & Mar & Apr & May & Jun & Jul & Aug & Sep & Oct & Nov & Dec \\
\hline Wheat & 11 & 9 & 9 & 5 & 3 & 3 & 9 & 14 & 11 & 7 & 8 & 11 \\
\hline Barley & 8 & 8 & 9 & 4 & 2 & 11 & 5 & 18 & 11 & 8 & 7 & 9 \\
\hline Oats & 13 & 3 & 10 & 15 & 3 & 4 & 6 & 11 & 10 & 8 & 7 & 10 \\
\hline Corn & 15 & 11 & 9 & 7 & 5 & 6 & 6 & 6 & 2 & 9 & 13 & 11 \\
\hline Sunflowers & 10 & 8 & 11 & 5 & 2 & 4 & 5 & 2 & 3 & 29 & 11 & 10 \\
\hline Edible Beans & 10 & 9 & 9 & 7 & 6 & 4 & 6 & 3 & 17 & 13 & 4 & 12 \\
\hline Soybeans & 15 & 6 & 3 & 2 & 1 & 1 & 2 & 1 & 6 & 40 & 14 & 9 \\
\hline
\end{tabular}


Now, an equation can be presented for computing peak daily truck trips to shuttle elevators:

(6) Peak Daily Trucks $=\exp (8.86876+0.50309 * \ln ($ cap $)) / \mathrm{BT} * \mathrm{ER} * \mathrm{PP} / \mathrm{DD}$

Where:

$\mathrm{PP}=$ Percent of truck deliveries in the peak month

$\mathrm{DD}=$ Delivery days in the month (assumed to exclude holidays and Sundays)

Similar equations can be derived from Equations 4 and 5 for unit-train and multi-car elevators, respectively. Peak-hour traffic can be estimated by assuming that truck deliveries are uniformly distributed over a 12-hour day.

\section{Outbound Truck Trips}

Although railroads transport most of the outbound traffic from elevators, trucks capture a share of outbound volume. In essence, some grain is moved into the elevator by truck, unloaded and elevated, and later shipped to market in another truck. Trucks moved only $5 \%$ of the outbound volume from the shuttletrain elevators analyzed in the North Dakota study. However, trucks moved about $20 \%$ of the outbound volume from unit-train elevators and about $45 \%$ of the volume from multi-car facilities. This outbound truck volume can be estimated from the predicted elevator throughput equations. For example, Equation 3 can be restated as: $\exp (8.86876+0.50309 * \ln (c a p)) * 1.05 / \mathrm{BT} * \mathrm{ER}$.

The outbound truck percentages depend upon the facility's location and many other factors. It is reasonable to assume that a very high percentage of this traffic moves in combination trucks.

\section{Truck Distribution}

The number of peak truck trips generated by an elevator depends upon the mix of trucks used to deliver the grain. Table 7 shows the observed distribution of combination and single-unit trucks on highways within 0.5 miles of a unit-train or shuttle-train elevator in North Dakota. The traffic data suggest that approximately $66 \%$ of the trucks in the vicinities of shuttle elevators are combination trucks such as the 3S2. In comparison, about $55 \%$ of the trucks in the vicinities of unit-train elevators are combination trucks.

Table 7. Percentages of Single-Unit and Combination Trucks in the Vicinities of Elevators

\begin{tabular}{|l|c|c|c|c|}
\hline \multirow{2}{*}{ Traffic Factor } & \multicolumn{2}{|c|}{ Unit-Train Elevators } & \multicolumn{2}{c|}{ Shuttle-Train Elevators } \\
\cline { 2 - 5 } & Mean & Std Dev & Mean & Std Dev \\
\hline Total AADT & 1,187 & 940 & 1,268 & 583 \\
\hline Truck AADT & 212 & 65 & 251 & 34 \\
\hline Pct. Single-Unit Trucks & $45 \%$ & $13 \%$ & $34 \%$ & $9 \%$ \\
\hline Pct. Combination Trucks & $55 \%$ & $13 \%$ & $66 \%$ & $9 \%$ \\
\hline
\end{tabular}

A higher percentage of trucks near multi-car elevators are combination trucks (approximately 66\%). This is explained by the relatively higher percentage of outbound truck shipments from these elevators as compared to the outbound truck shipments from unit-train elevators.

These truck-type distributions can be used to compute weighted-average bushels per truck (BT) for use in the trip generation equations. About $85 \%$ of the single-unit trucks owned by farmers in the Northern Plains region are 3-axle trucks-i.e., trucks with a tandem rear axle (6). The average load in these trucks is approximately 15.5 tons or 560 bushels. 


\section{Truck Trip Tables}

The number of predicted inbound equivalent truck trips is calculated by dividing the predicted throughput by the weighted average truck capacity or equivalent truck value and are shown in Tables 8 and 9 . The number of predicted total equivalent trucks is calculated by adding the predicted inbound and predicted outbound equivalent truck trips. The ESAL value for each truck type was obtained from the AASHTO Guide for Design of Pavement Structures (7), and a weighted-average ESAL factor was calculated and multiplied by the total predicted truck trips. ESAL factors by truck type are given in Table 10.

Table 8. Predicted Equivalent Truck Trips and ESAL Factors for Shuttle Elevators

\begin{tabular}{|c|c|c|c|}
\hline $\begin{array}{c}\text { Elevator Capacity } \\
\text { (Thou. Bushels) }\end{array}$ & $\begin{array}{c}\text { Predicted Inbound } \\
\text { Equivalent Trucks }\end{array}$ & $\begin{array}{c}\text { Predicted Total Equivalent } \\
\text { Trucks }\end{array}$ & Predicted ESALs \\
\hline 1,000 & 19,297 & 20,262 & 21,170 \\
\hline 1,250 & 21,592 & 22,672 & 23,687 \\
\hline 1,500 & 23,666 & 24,849 & 25,963 \\
\hline 1,750 & 25,573 & 26,852 & 28,055 \\
\hline 2,000 & 27,350 & 28,718 & 30,005 \\
\hline 2,250 & 29,021 & 30,472 & 31,837 \\
\hline 2,500 & 30,600 & 32,130 & 33,570 \\
\hline 2,750 & 32,102 & 33,707 & 35,217 \\
\hline 3,000 & 33,538 & 35,215 & 36,793 \\
\hline 3,250 & 34,917 & 36,663 & 38,306 \\
\hline 3,500 & 36,244 & 38,056 & 40,890 \\
\hline 3,700 & 37,272 & 39,136 & \\
\hline
\end{tabular}

Table 9. Predicted Equivalent Truck Trips and ESAL Factors for Unit-Train Elevators

\begin{tabular}{|c|c|c|c|}
\hline $\begin{array}{c}\text { Elevator Capacity } \\
\text { (Thou. Bushels) }\end{array}$ & $\begin{array}{c}\text { Predicted Inbound } \\
\text { Equivalent Trucks }\end{array}$ & $\begin{array}{c}\text { Predicted Total } \\
\text { Equivalent Trucks }\end{array}$ & Predicted ESALs \\
\hline 750 & 7,991 & 9,589 & 9,301 \\
\hline 1,000 & 9,233 & 11,079 & 10,747 \\
\hline 1,250 & 10,330 & 12,396 & 12,023 \\
\hline 1,500 & 11,322 & 13,587 & 13,179 \\
\hline 1,750 & 12,236 & 14,683 & 14,242 \\
\hline 2,000 & 13,086 & 15,703 & 15,231 \\
\hline 2,250 & 13,886 & 16,664 & 16,163 \\
\hline 2,500 & 14,640 & 17,569 & 17,041 \\
\hline 2,750 & 15,362 & 18,434 & 17,880 \\
\hline 3,000 & 16,047 & 19,257 & 18,678 \\
\hline 3,250 & 16,708 & 20,050 & 19,447 \\
\hline
\end{tabular}

These tables show the impact of elevator capacity and truck-type distribution on the number of ESALs generated. Shuttle elevators generate more ESALs per equivalent truck trips than unit-train elevators due to the higher percentage of combination 5-axle trucks used for the movements. 
Table 10. ESAL Factors by Truck Type

\begin{tabular}{|c|c|c|}
\hline Truck Type & ESALs & ESALs per Ton-Mile \\
\hline SU-3 & 1.479 & 0.102 \\
\hline SU-4 & 1.060 & 0.066 \\
\hline 3-S2 & 2.719 & 0.105 \\
\hline 3-S2-2 & 3.410 & 0.095 \\
\hline
\end{tabular}




\section{CONCLUSION}

This study was conducted to estimate trip-rate equations for grain elevators using publicly available data. Because trip rates can be estimated from facility characteristics, the equations should be generally transferable and easily applicable to highway sketch planning. Since the survey reflects the crop patterns and characteristics of North Dakota, the trip rates may not reflect extreme values, such as very dense production regions or terminal river elevators.

A double-log model was estimated with throughput as a function of elevator type and capacity using data obtained through the North Dakota Public Service Commission. A variety of tests were performed to ensure the regression assumptions were met and that the model possessed sound predictive capabilities. Predictive equations for elevator throughput were derived from the model for shuttle-train, unit-train, and multi-car elevators. Equations for annual truck deliveries and peak daily trucks were also derived in the study.

The impact of the truck trips generated by grain elevators is dependent on the type of trucks used for the movements. Analysis of grain movement data indicates that shuttle-train elevators favor the use of 5-axle combination trucks, while unit-train elevators utilize a higher percentage of single-unit trucks. The number of ESALs per truck trip was higher for shuttle-train elevators in North Dakota than for unit-train elevators, and is due to the varying truck distribution.

Note: An abbreviated version of this document has been peer reviewed and accepted for publication in the Transportation Research Record. 


\section{REFERENCES}

1. Trip Generation - Volume Two. Institute of Transportation Engineers, Washington, D.C., 1997.

2. NCHRP Synthesis 298 - Truck Trip Generation Data: A Synthesis of Highway Practice. National Cooperative Highway Research Program, Transportation Research Board - National Research Council, Washington, D.C., 2001.

3. Vachal, Kimberly, Brenda M. Lantz, John Bitzan, Mark Berwick, and Denver Tolliver. North Dakota Strategic Freight Analysis: Agricultural Sector - Summary Report. Upper Great Plains Transportation Institute, Fargo, N.D., MPC-01-127.5, 2001.

4. North Dakota Agricultural Statistics 2005. North Dakota Agricultural Statistics Service, ND-NASS, Fargo, N.D., 2005.

5. Pindyck, Robert S. and Daniel L. Rubinfeld. Econometric Models \& Economic Forecasts: $4^{\text {th }}$ Edition. McGraw-Hill, New York, 1997.

6. Tolliver, Denver, Mark Berwick, Kimberly Vachal. Farm-to-Market Transportation Patterns and Truck Use in the Northern Plains. Upper Great Plains Transportation Institute, DP-167.

7. AASHTO Guide for Design of Pavement Structures, American Association of State Highway and Transportation Officials (AASHTO), Washington, D.C., 1992, D6-D8. 